\title{
Analysis and Modelling of Effects of Traffic Light Operations Variability to Violation Rates at Junction
}

\author{
Fabio Galatioto ${ }^{1}$, Tullio Giuffrè ${ }^{2}$, Margaret C. Bell ${ }^{1} \&$ Giovanni Tesoriere ${ }^{2}$ \\ ${ }^{1}$ School of Civil Engineering and Geosciences, Newcastle University, Newcastle upon Tyne, United Kingdom \\ ${ }^{2}$ Faculty of Engineering and Architecture, Kore University of Enna, Enna, Italy \\ Correspondence: Tullio Giuffrè, Faculty of Engineering and Architecture, Kore University of Enna, Cittadella \\ Universitaria, Enna 94100, Italy. Tel: 39-935-536-356. E-mail: tullio.giuffre@unikore.it
}

Received: September 7, 2012

Accepted: September 23, $2012 \quad$ Online Published: September 26, 2012

doi:10.5539/mas.v6n10p53

URL: http://dx.doi.org/10.5539/mas.v6n10p53

\begin{abstract}
Previous research, based on potential conflicts analysis, has provided a quantitative evaluation of 'proneness' to red-light running (RLR) behaviour at urban signalised intersections (Giuffrè \& Rinelli, 2006) varying geometric, traffic flow and driver characteristics. Recent study (Bell, Galatioto, Giuffrè, \& Tesoriere, 2012) demonstrated the potential to use micro-simulation models to evaluate the 'proneness' to RLR behaviour at urban signalised intersections in Italian cities, varying flow characteristics and stop line distances.

The micro-simulation, although at its early stages of development, has shown promise in its ability to model unintentional RLR behaviour and to evaluate alternative junction designs on proneness.

In order to make more robust the new modelling framework, the need to demonstrate the transferability of the modelling approach has been addressed in this paper by using a four arms junction in Enna (Italy), where an extensive period of continuous video recording has been carried out. Moreover, in collaboration with the local Police, different cycle and green time settings have been implemented in order to measure the effects on the RLR rates. Then the measured RLR rates have been evaluated and compared to the modelling results as a validation exercise. In this way the prediction capability of the proposed potential conflict model has been extended and improved.
\end{abstract}

Keywords: urban intersection, traffic light operation, violation analysis, microsimulation, road design evaluation, proneness to RLR

\section{Introduction}

Evidence of the human and financial cost to individuals and Governments (Retting \& Williams, 1996) of Red-Light Running (RLR) at signalised junctions has led to several studies over the recent decades. Also, various research (Mohamedshah, Chen, \& Council, 2000; Milazzo, Hummer, \& Prothe, 2001) analysed the effects of the RLR phenomenon on road safety. They all highlight both a very high frequency and the respective magnitude of the consequences (Wissinger, 2000).

Recently, the European Parliament and Europe Council (CEC, 2008) identified red-light running as one of the greatest causes of crashes, along with speeding, drunk-driving, and not using a seatbelt. This is confirmed also in other areas around the world such as U.S. where a study of accident data from four States (Mohamedshah et al., 2000) shown that RLR crashes account for up to 20 percent of the total crashes at urban signalised intersection.

As referring by Giuffrè and Rinelli (2006) and according to Elmitiny, Yan, Radwan, Russo and Nashara (2010) proneness to RLR behaviour can be associated to two main factors which determine - when circumstances make it possible - the choice to stop, or to proceed, at the junction. These are:

-human factors, related to population characteristics;

-road factors, depending on traffic, geometric and operational characteristics at the intersection.

Several behavioural studies have highlighted the role of the 2 main contributing features on RLR in terms of "dilemma zone" (Allos \& Al Haidithi, 1992) and situations that make RLR possible (Bonneson, Brewer, \& Zimmerman, 2001). Data analysis carried out by Campbell, Smith and Najm (2004) allowed building some logistic regression models to examine violators' vehicle speed and time after red when they crossed the 
intersection after the onset of the red signal.

Particularly in urban areas, many studies have been developed both on safety at signalised intersections - refer to Giuffrè, Granà, Marino, and Corriere (2011) - and on the set up of the traffic light signal timings, that is crucial to ensure that driver are likely to respect the signals. The FHWA (2003) suggests that the traffic light signal timings should be reviewed and updated regularly (every two years) in order to adapt the timings to the modified traffic demands. In particular, well-defined traffic light signal timing can reduce driver frustration resulting from extremely short or extremely long cycle duration (Kennedy \& Sexton, 2009).

The setup of the traffic light signal timings and phases is based on the specific characteristics of the junction and the single approaches. There are philosophies and studies that indicate both shorter and longer cycle duration for reducing violations at signalised junction (Sze, Wong, Pei, Choi, \& Lo, 2011; Koh \& Wong, 2007). A driver that expects to wait for a not excessive period of time may be less prone to accelerate to beat the amber or to run during the red phase. Different studies, summarised by (Chodur, Ostrowski, \& Tracz, 2011) shown the effects of cycle length vary on traffic and driver.

Although acknowledging that the human factors component of RLR is important, different studies in the past have considered the qualitative influence of both human, vehicle and road factors. From an engineering point of view the availability of qualitative data alone is insufficient in order to establish appropriate countermeasures against the RLR phenomenon on the decision making process. For this reason there is also a strong need to evaluate quantitatively the proneness to RLR. However, availability of this quantitative data is scarce.

Recent application from the authors Bell, Galatioto, Giuffrè, and Tesoriere (2010), and Bell et al. (2012) have tried to extend the traditional empirical and probabilistic approaches by assessing the proneness to RLR using a micro-simulation model in a signalised junction. In this first attempt it was demonstrated how the modelling tool has potential capability to evaluate the effect of geometric designs, operational conditions and traffic flow volumes on the unintentional RLR violation rates. Because of the potential value for traffic operators and Local Authorities of the extended use of existing micro-simulation models, already setup in their areas of competences and cities, to identify potential high risk junctions and road layouts, this paper demonstrates how the same above mentioned approach can be transferred into a different study site.

Moreover, acknowledging that RLRs behaviour is influenced by the traffic light timings, usually setup to optimise traffic movements at junctions, and related delays and stops, the authors in collaboration with the local police defined two sets of traffic light cycles and several green times changes in order to measure how the RLR rates will be affected.

Finally, this paper seeks to calibrate and validate a micro-simulation tool that could be used to minimise proneness of RLR at the design stage. The junction used for the research is described in the following case study section. The paper will continue describing the potential for the validated micro-simulation model to predict the proneness of links / streams to RLR. Finally, the micro-simulation method validated here will provide evidence of its potential use to explore, at a design stage, different geometric layouts and traffic light control strategies.

\section{Case Study}

A road intersection (see Figure 1) in Enna, Italy, was studied in detail over an extensive period of 13 days.

Numerous business activities characterise the study area, such as bars, offices overlooking arms 2 and 3, while in the left side on the corner between arm 1 and 4 there is the elementary school "De Amicis". Other businesses (such as banks, wine bars, restaurants) are in close proximity of the intersection, increasing the pedestrian movements especially during day time. Moreover, the intersection connects the city to the area used for the weekly market placed at the Europa square.

The location and type of businesses in the area studied are identified in detail in Figure 1 (right).

The red-light running information have been collected by manual on-street measurements and validated using video surveys used to monitor traffic flows and speed over the survey period.

The junction is a typical four arm intersection with a main road, namely Viale Diaz, indicated in Figure 1 with arm 1 and 3, both two ways and one lane road; and a secondary road, namely Via Libertà, with arm 2 and 4, where arm 2 is a two lanes one way road and arm 4 a two ways road with one lane for each direction.

The intersection as represented in Figure 1 (left) is an isolated signalised junction. Only other priority junctions are present in close proximity of the junction studied, for clarity in Figure 1 (left) the 2 closer priority junctions in each arm have been represented. This condition provides an arrival pattern which is not dependent on other traffic light timings avoiding platoon arrival patterns as well. 


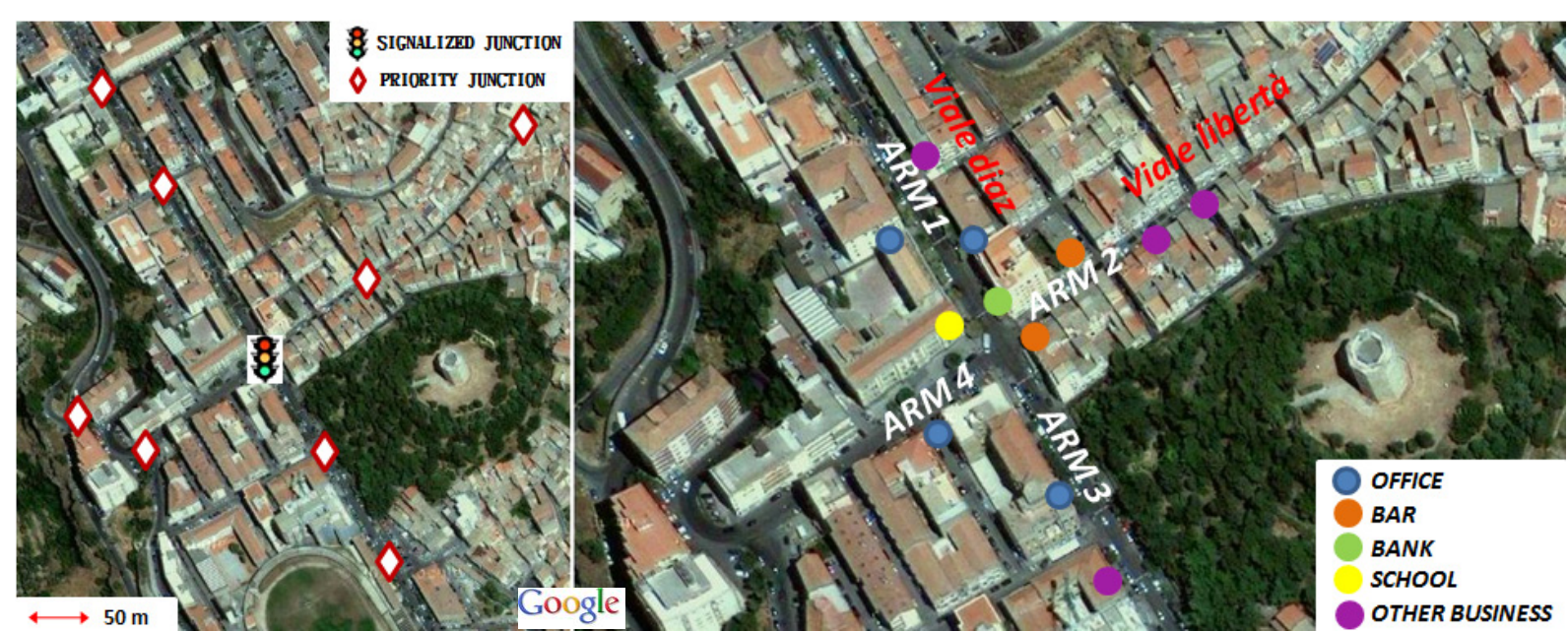

Figure 1. Type of junctions (left) and layout of the signalised intersection studied in Enna, with characterisation of business activities (right)

The duration of the traffic-light cycle (C) before the modification made for the purpose of this study, was equal to 84 seconds. During the monitoring period a variation of the traffic-light cycle has been setup according to the following modifications:

- increase of traffic light cycle from 84 to 94 seconds;

- variation of green and red time keeping the duration of the cycle constant.

In Table 1 are presented for the two directions the different traffic light timings setup through the monitoring period.

Table 1. Traffic signal phasing during the observation period

\begin{tabular}{ccccccccccc}
\hline \multicolumn{1}{c}{ Main direction - Viale Diaz } & \multicolumn{1}{c}{ Secondary direction - via Libertà } \\
\hline day & green & red & AR & yellow & Cycle & green & red & AR & yellow & Cycle \\
1 & 30 & 49 & 3 & 5 & 84 & 40 & 39 & 3 & 5 & 84 \\
2 & 55 & 34 & 3 & 5 & 94 & 25 & 64 & 3 & 5 & 94 \\
3 & 45 & 44 & 3 & 5 & 94 & 35 & 54 & 3 & 5 & 94 \\
4 & 55 & 34 & 3 & 5 & 94 & 25 & 64 & 3 & 5 & 94 \\
5 & 50 & 39 & 3 & 5 & 94 & 30 & 59 & 3 & 5 & 94 \\
6 & 50 & 29 & 3 & 5 & 84 & 20 & 59 & 3 & 5 & 84 \\
7 & 25 & 64 & 3 & 5 & 94 & 55 & 34 & 3 & 5 & 94 \\
8 & 40 & 39 & 3 & 5 & 84 & 30 & 49 & 3 & 5 & 84 \\
9 & 40 & 39 & 3 & 5 & 84 & 30 & 49 & 3 & 5 & 84 \\
10 & 40 & 39 & 3 & 5 & 84 & 30 & 49 & 3 & 5 & 84 \\
11 & 40 & 39 & 3 & 5 & 84 & 30 & 49 & 3 & 5 & 84 \\
12 & 40 & 39 & 3 & 5 & 84 & 30 & 49 & 3 & 5 & 84 \\
13 & 40 & 39 & 3 & 5 & 84 & 30 & 49 & 3 & 5 & 84 \\
\hline
\end{tabular}

The traffic light cycle consists of 2 phases along the two roads. During the monitoring period the traffic light cycle was modified for a period of 7 days while for the remaining 6 days was maintained identical to the original standard duration.

The traffic light duration has been modified according to Table 1 timings mainly for the purpose of testing the variability of violations and unintentional RLR rates as a consequence of the different traffic light settings. As 
the volumes of traffic for the different arms were on the range 100 up to 1,000 vehicles per hour, with the highest flow coming from Via Liberta' arm 2, which has 2 lanes, the capacity of each link was considerably greater than the maximum flow measured with expected Level of Services A or B. However, in this paper was not assessed the performance of each traffic light setting in term of Level of Services.

With reference to Figure 2 there is a clear underlying trend between day 1 and day 8 of progressive reduction of the number of violations in the main direction, while in the remaining period, when the traffic light setup was maintained constant and equal to day 1 , it shows a progressive increment of the violation toward a rate similar to the beginning of the survey period.

In Figure 2 are presented the number of violations and the cycle times (in seconds) along the main and secondary roads.

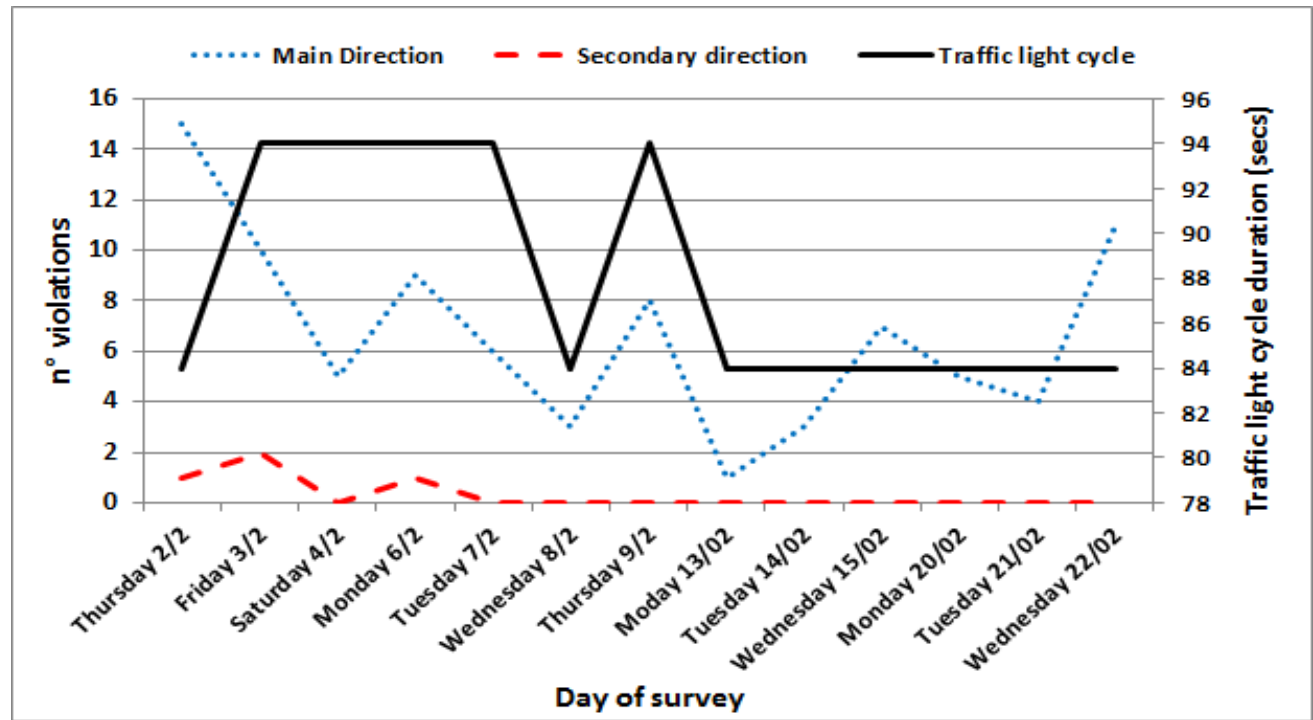

Figure 2. Number of violations and related traffic light cycle during the 13 days of observation along the main and secondary roads

During weekdays the daily traffic of the junction is 11,500 vehicles, while on the main road is 7,300 veh/day and $4,200 \mathrm{veh} /$ day on the secondary road.

\section{On-site Measurements}

After the validation exercise, it was possible to assume that the actual RLRs events were equal to the violations observed. Table 2 aggregates the violation rates based on violation/hour, violation/1,000 vehicles and violation per 10000 vehicles-cycle for the selected intersection.

The collection of the data, using video recording, postprocessing and manual techniques was carried out on a daily basis for 11 hours of relief on both directions from 7:30 to 13:30 and from 15:30 to 20:30.

Table 2. Violation rates for the selected intersection over the observation period

\begin{tabular}{ccccccccccc}
\hline & \multicolumn{4}{c}{ Main direction } & \multicolumn{7}{c}{ Secondary direction } \\
\hline & & $\begin{array}{c}\text { N. } \\
\text { violation } \\
\text { (11 hours) }\end{array}$ & $\begin{array}{c}\text { Viol / } \\
\text { hour }\end{array}$ & $\begin{array}{c}\text { Viol/ } \\
1,000 \\
\text { veh }\end{array}$ & $\begin{array}{c}\text { Violations } \\
\text { per } 10000 \\
\text { veh-cycle }\end{array}$ & $\begin{array}{c}\text { N. } \\
\text { violation } \\
(11 \text { hours })\end{array}$ & $\begin{array}{c}\text { Viol / } \\
\text { hour }\end{array}$ & $\begin{array}{c}\text { Viol / } \\
1,000 \\
\text { veh }\end{array}$ & $\begin{array}{c}\text { Violations } \\
\text { per 10 000 } \\
\text { veh-cycle }\end{array}$ & $\begin{array}{c}\text { Traffic } \\
\text { Light } \\
\text { Cycle }\end{array}$ \\
\hline 1 & Thu 02/02/2012 & 15 & 1.364 & 1.763 & 0.037 & 1 & 0.091 & 0.341 & 0.007 & 84 \\
2 & Fri 03/02/12 & 10 & 0.909 & 1.154 & 0.027 & 2 & 0.182 & 1.134 & 0.027 & 94 \\
3 & Sat 04/02/12 & 5 & 0.455 & 0.747 & 0.018 & 0 & 0 & 0 & 0 & 94 \\
4 & Mon 06/02/12 & 9 & 0.818 & 0.938 & 0.022 & 1 & 0.091 & 0.445 & 0.011 & 94 \\
5 & Tue 07/02/12 & 6 & 0.545 & 0.753 & 0.018 & 0 & 0 & 0 & 0 & 94
\end{tabular}




\begin{tabular}{ccccccccccc}
6 & Wed 08/02/12 & 3 & 0.273 & 0.433 & 0.009 & 0 & 0 & 0 & 0 & 84 \\
7 & Thu 09/02/12 & 8 & 0.727 & 0.928 & 0.022 & 0 & 0 & 0 & 0 & 94 \\
8 & Mon 13/02/12 & 1 & 0.091 & 0.157 & 0.003 & 0 & 0 & 0 & 0 & 84 \\
9 & Tue $14 / 02 / 12$ & 3 & 0.273 & 0.402 & 0.009 & 0 & 0 & 0 & 0 & 84 \\
10 & Wed 15/02/12 & 7 & 0.636 & 0.954 & 0.020 & 0 & 0 & 0 & 0 & 84 \\
11 & Mon 20/02/12 & 5 & 0.455 & 0.624 & 0.013 & 0 & 0 & 0 & 0 & 84 \\
12 & Tue2 $1 / 02 / 12$ & 4 & 0.364 & 0.438 & 0.009 & 0 & 0 & 0 & 0 & 84 \\
13 & Wed 22/02/12 & 11 & 1.00 & 1.195 & 0.025 & 0 & 0 & 0 & 0 & 84 \\
\hline
\end{tabular}

\section{Microsimulation Tool Description}

Microscosimulation models are considered the most powerful and appropriate traffic analysis tools when the aim is to reproduce movements of individual vehicle in a network (through junctions, along section of roads, etc.). In this paper a novel approach to modelling RLR with traffic micro-simulation demonstrated in (Bell et al., 2012) has been applied to demonstrate the transferability of the approach and to evaluate the ability of the micro-simulation model to reproduce the RLR phenomena when traffic light operations (Cycle and green timings) changes. For consistency of the results and to demonstrate the transferability of Bell et al. (2012) approach the AIMSUN model (http://www.aimsun.com/wp/) was used.

The microsimulation model has been setup to represent the 4 arm junction studied, including traffic light setup, pedestrian crossings and stop-line. Different parameters, such as reaction time at traffic light stop-line, max/min acceleration and deceleration, headway and speed limit have been included to improve the capacity of the model to reflect driver behaviour at the signalised intersection simulated. Hourly Origin-Destination matrices for each of the 11 hours monitored each day have been setup using the traffic flow measurements made during the survey period.

\section{Validation and Discussion of the Micro-simulation Model of RLR}

A validation exercise has been carried out in order to assess the model performance against the ability to reproduce measured data. The comparison of flows, from direct observation, with those predicted, from the microsimulation shows a very good agreement (with a regression coefficient of $\mathrm{R}^{2}$ of 0.99 , Figure 3 ) for the whole flow range, 110 to 1,080 vehicles per hour, measured at the junction.

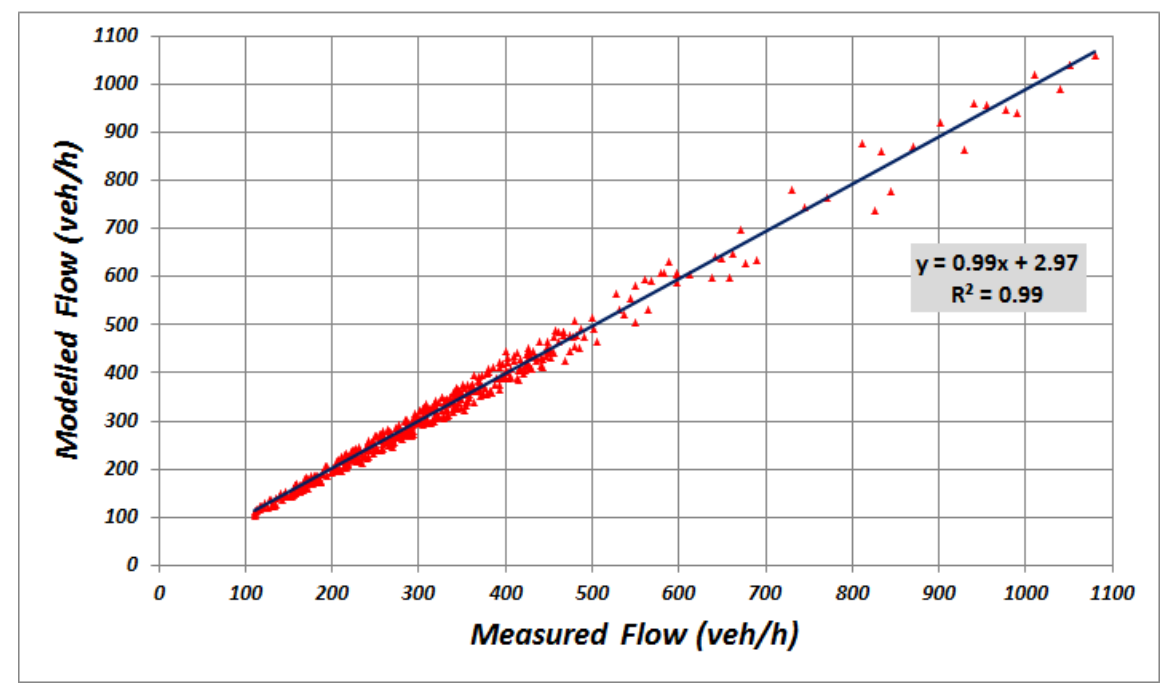

Figure 3. Validation of the simulation model used at the junction studied

It is important to mention that the model was able to reproduce to such a high level of performance the traffic at the studied junction due to the richness of data available as well as to the relatively straight forward junction geometry, and the richness of the speed and flow information, of essentially an isolated junction with fixed time plans. 
In order to simulate the RLR events, and adopting the same methodology used in Bell et al. (2012), the micro simulation model was set up with a double traffic light at each entry link, one representing the existing traffic light and the second, few metres further down, used as a virtual one. The double traffic light sets per link have been set up with same cycle time and with different offsets ( 0 to 4 secs with $1 \mathrm{sec}$ steps) to ensure that as the vehicle crosses the first stop-line, it is presented with a green with 1,2,3 and 4 seconds delay to the start of the red to stop at the following stop-line. In this way, the two possible behaviours, decelerating to stop and accelerating to pass through the junction (in reality during the amber), equivalent to a violation, were modelled. This approach was adopted because the micro-simulator is set up not to allow vehicles to cross a stop-line during the red, thus only the unintentional RLR behaviours have been modelled. The collection of the violations data for the post-processing and analysis was made possible by locating two sets of detectors to count the number of vehicles crossing second by second, specifically for the time period after the amber starts, to evaluate the number of violation for each cycle (see Figure 4).
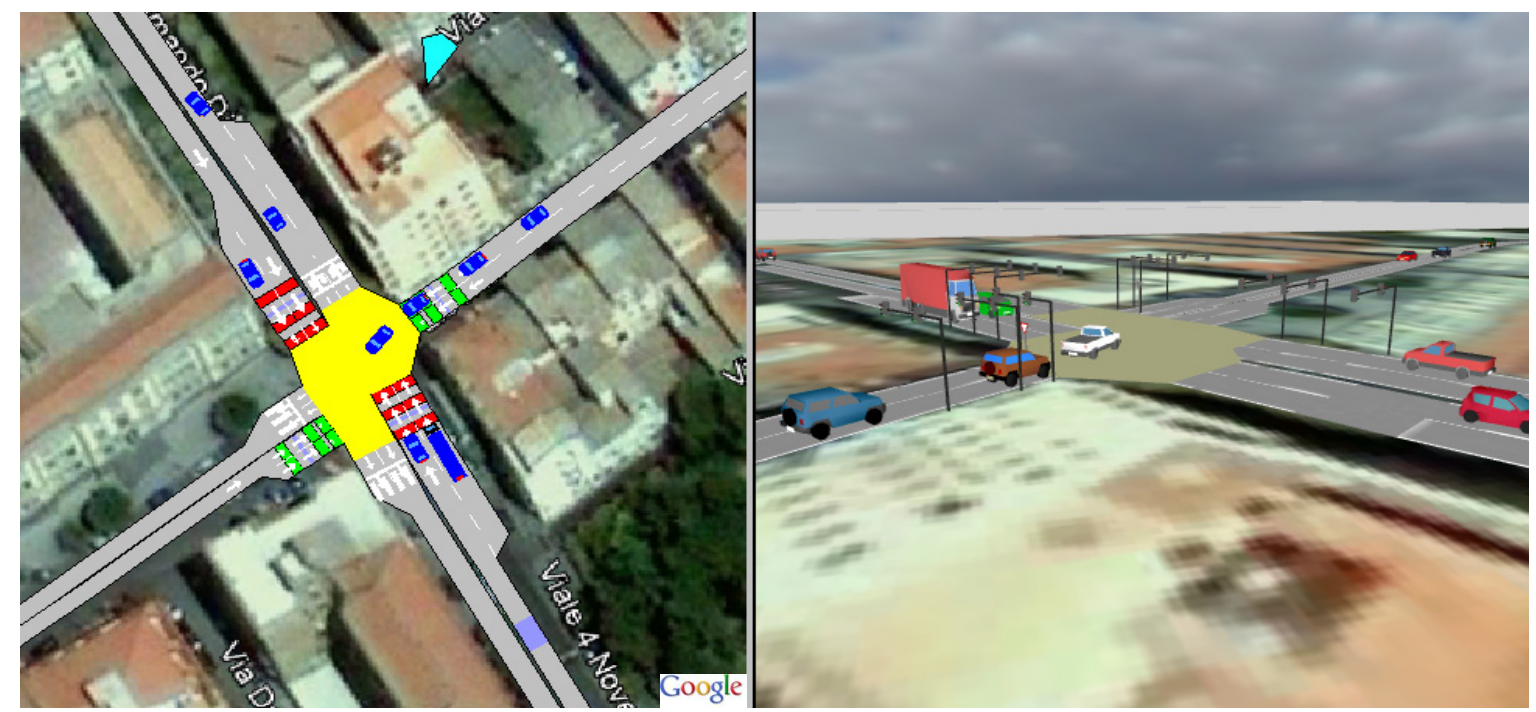

Figure 4. RLR microsimulation model layout in 2D (left) and 3D (right)

In order to identify the modelled violations, vehicles crossing the stop line during the amber have been extrapolated from the model outputs using a filtering algorithm.

In Figure 5 an example of how the microsimulation model represents the vehicle crossing during the amber and generating an unintentional violation.

To carry out the RLR microsimulation model analysis hourly matrices between 7:30 hrs and 22:30 hrs, for the 13 days of observations have been prepared and imported into AIMSUN.

Five runs per scenario have been produced in order to calculate the average value of the number of unintentional violations associated to the main and secondary directions.

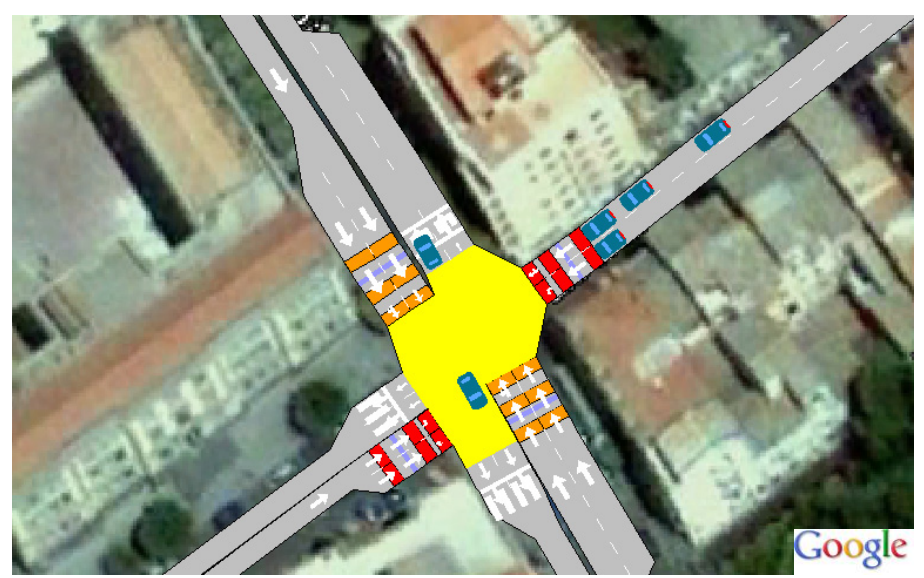

Figure 5. Unintentional RLR microsimulation 


\section{Comparison of RLR Measurements with Microsimulation Results}

The results obtained from the microsimulation model analysis are represented and compared in Figure 6.

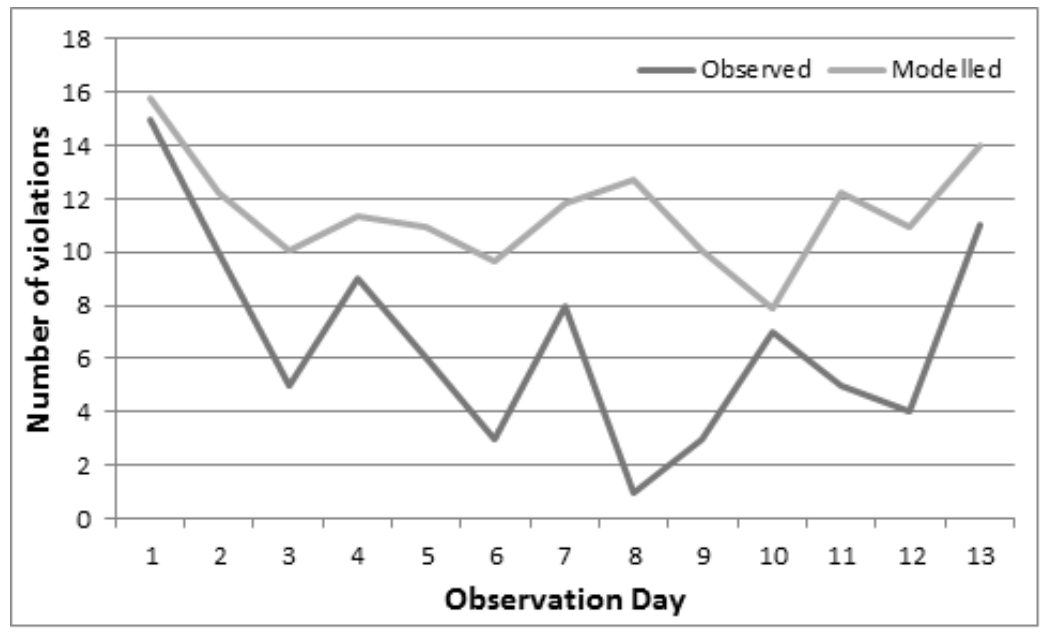

Figure 6. Observed and modelled violations during the 13 days of observation and simulation

The microsimulation performs well at the beginning and at the end of the observed period with small differences, this is probably due to the fact that microsimulation model and the representation of driver behaviour is more similar to a long-term observation with the same traffic light setup, where the usual drivers know well the timings and are more aggressive and take more risks. In fact while between the $3^{\text {rd }}$ and $12^{\text {th }}$ day most of the observation show a similar behaviour/trend, the simulated violations are generally greater than the observed ones. This it is probably due to the fact that during the $3^{\text {rd }}$ and $8^{\text {th }}$ day the traffic light setup has been changed daily generating uncertainty to the usual drivers who felt less confident and then less aggressive, leading to a substantial reduction on the number of violations with the minimum of 1 violation the $8^{\text {th }}$ day. For this reason the microsimulation model results can be considered as an upper limit of the number of violation expected to occur in the junction for a certain traffic light setup and a certain traffic flow. In fact at the end of the period of observation the difference between simulated and observed violations reduce to 3 .

Finally, Between the $8^{\text {th }}$ and $11^{\text {th }}$ day the microsimulation presents opposite trend if compared to the measurements, day 8 is the first day of the constant setup after a week of continuous changes in traffic-light cycle and green, this could be the reason of a specific and very different behaviour from the drivers that after day $11^{\text {th }}$ restart to match the simulation trend.

The information collected during the 13 days of survey highlighted that the variability of the traffic light settings sensibly influenced the number of violation rates by reducing the total numbers, this suggests that a possible countermeasure could be the implementation of an actuated traffic light that accommodating the variations of traffic flows during the day will modify the cycle and green timings generating a limited but effective variability that could replicate the changes implemented during the 13 days of survey. This is expected to produce the beneficial effects measured. Moreover, looking in detail at the junction layout and on-street parking characteristics (Figure 7), another potential countermeasure could be to implement the prohibition of on-street parking in close proximity of the junction, in particular on the right hand side where the traffic signal is located (Figure 7), this will improve significantly the visibility of the traffic signal at a sufficient distance and will capture the drivers' attention with positive effects by reducing the unintentional violations. 


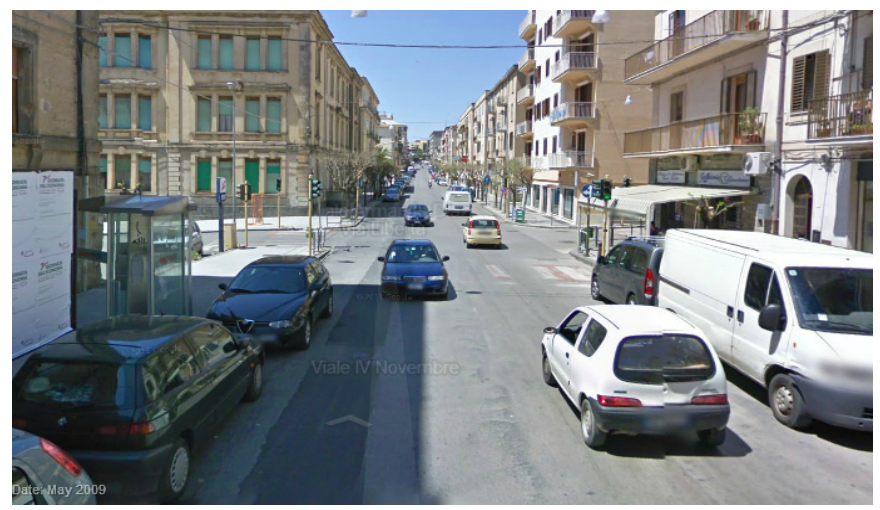

Figure 7. View of the junction studied from Viale Diaz

\section{Conclusions}

Building on the findings from previous study from the authors (Bell et al., 2012), in this paper, a detailed analysis of the violations occurred in a 4 arm junction in Enna has been carried out and interesting patterns of the evolution and variation of the number of violation varying the traffic light setup of the junction have been identified.

By testing the new modelling framework using the signalised junction in Enna the first step of a more comprehensive transferability exercise of the modelling approach has been addressed in this paper, also the variability of the traffic light settings allows to make more robust the modelling framework. The comparison between the modelled and observed violation confirms that, except between the $8^{\text {th }}$ and $11^{\text {th }}$ day, the microsimulation model performs well in predicting the number of unintentional RLR violations, while when changing daily the timings/cycle the number of observed violations is lower than the modelled, but it follows the same trend.

However, between the $8^{\text {th }}$ and $11^{\text {th }}$ day, this preliminary study highlighted a different prediction of RLR violations from the model this, associated to the limited number of days of survey, in particular from day 8 when a constant traffic-light setup has been implemented after a week of modification, clearly identifies an area where further research is required.

These results although encouraging and broadly consistent with the previous study, suggest the need of further investigation on the adaptability of the drivers to the different traffic-light setup, in particular it is anticipated that a more comprehensive survey covering a longer period of observation with limited variation of traffic light timings through each survey period will be developed as part of a future study.

Moreover, while this paper provides other evidence of the potential of the methodological approach developed in Bell et al. (2012) it is intention of the authors to continue to test and diversify the case studies in future research in order to make more robust and consistent the findings and the method adopted.

Finally, because of the potential value for traffic operators and Local Authorities of the extended use of existing micro-simulation models it is needed and planned by the authors to carry out a comprehensive assessment of the entire area of an existing micro-simulation, in order to explore the potential of this approach to identify relationships between violation rates and layout, signal settings and traffic flow volumes of the signalised junctions within the entire area.

\section{References}

Allos, A. E., \& Al Haidithi, M. I. (1992). Driver Behavior During Onset of Amber at Signalized Junctions. Traffic Engineering and Control, 33(5), 312-317.

Bell, M. C., Galatioto, F., Giuffrè, T., \& Tesoriere, G. (2010). An extended analysis of red-light violation model using traffic micro-simulation. proceeding $8^{\text {th }}$ Malaysian Road Conference \& Exhibition 2010, October 2010, Kuala Lumpur (Malaysia).

Bell, M. C., Galatioto, F., Giuffrè, T., \& Tesoriere, G. (2012). Novel application of red-light runner proneness theory within traffic microsimulation to an actual signal junction. Accident Analysis \& Prevention, 46, 26-36. http://dx.doi.org/10.1016/j.aap.2011.12.010

Bonneson, J., Brewer, M., \& Zimmerman, K. (2001). Review and Evaluation of Factors that Affect the 
Frequency of Red Light-Running. FHWA/TX-02/4027-1, Washington, DC: Federal Highway Administration.

Campbell, B. N., Smith, J. D., \& Najm, W. G. (2004). Analysis of Fatal Crashes Due to Signal and Stop Sign Violations. Washington D.C. (USA), Department of Transportation DOT HS 809779.

CEC (Commission of the European Communities). (2008). Proposal for a Directive of the European Parliament and of the Council Facilitating Cross-boarder Enforcement in the Field of Road Safety, COM (2008) 0151, Brussels.

Chodur, J., Ostrowski, K., \& Tracz, M. (2011). Impact of Saturation Flow Changes on Performance of Traffic Lanes at Signalised Intersections. Procedia - Social and Behavioral Sciences, 16, 600-611. http://dx.doi.org/10.1016/j.sbspro.2011.04.480

Elmitiny, N., Yan, X., Radwan, E., Russo, C., \& Nashara, D. (2010). Classification analysis of driver's stop/go decision and red-light running violation. Accident Analysis and Prevention, 42, 101-111. http://dx.doi.org/10.1016/j.aap.2009.07.007

Federal Highway Administration. (2003) Making Intersections Safer: A Toolbox of Engineering Countermeasures to Reduce Red-Light-Running. An Informational Report. Institute of Transportation Engineers, Publication No. IR-115, ISBN: 0-935403-76-0, Washington DC, USA.

Giuffrè, O., Granà, A., Marino, R., \& Corriere, F. (2011). Handling underdispersion in calibrating safety performance function at Urban, four-leg, signalized intersections. Journal of Transportation Safety and Security, 3(3), 174-188. http://dx.doi.org/10.1080/19439962.2011.599014

Giuffrè, T., \& Rinelli, S. (2006). Evaluation of proneness to red light violation. A quantitative approach. Transportation Research Record, 1969, 112-119. Retrieved from http://www.aimsun.com/wp/ (01/09/2012)

Kennedy, J., \& Sexton, B. (2009). Literature Review of Road Safety at Traffic Signals and Signalised Crossings. Published Project Report (PPR436), Transport Research Laboratory.

Koh, P. P., \& Wong, Y. D. (2007). Driving situations and driver decisions at road traffic signals. Journal of Advanced Transportation, 41, 53-68. http://dx.doi.org/10.1002/atr.5670410105

Milazzo, J. S., Hummer, J. E., \& Prothe, L. M. (2001). A Recommended Policy of Automated Electronic Traffic Enforcement of Red Light Running Violations in North Carolina. Final Report, Institute for Transportation Research and Education, North Carolina State University, Raleigh, N.C.

Mohamedshah, Y. M., Chen, L. W., \& Council, F. M. (2000). Association of Selected Intersection Factors with Red-Light Running Crashes. Publication FHWA RD-00-112. FHWA, U.S. Department of Transportation.

Retting, R. A., \& Williams, A. F. (1996). Characteristics of Red Light Violators: Results of a Field Investigation. Journal of Safety Research, 27(1), 9-15.

Sze, N. N., Wong, S. C., Pei, X., Choi, P. W., \& Lo, Y. K. (2011). Is a combined enforcement and penalty strategy effective in combating red light violations? An aggregate model of violation behavior in Hong Kong. Accident Analysis \& Prevention, 43(1), 265-271. http:// dx.doi.org/10.1016/j.aap.2010.08.020

Wissinger, L. M. (2000). Issues Surrounding the Operation and Installation of Red Light Cameras. Master's thesis. N. C. State University. 